\title{
HUBUNGAN KUALITAS TIDUR, AKTIVITAS FISIK DAN TINGKAT STRES DENGAN KEJADIAN DISMENOREA PRIMER PADA MAHASISWI FAKULTAS KESEHATAN MASYARAKAT UNIVERSITAS HALU OLEO
}

\author{
Ayu Delia $\mathbf{Y}^{1}$ Lymbran Tina ${ }^{2}$ Jusniar Rusli Afa ${ }^{3}$ \\ 1,2,3 Fakultas Kesehatan Masyarakat Universitas Halu Oleo Kendari \\ 1ayudeliay@gmail.com²lymbranizzah@gmail.com³jusniar.rusliafa@uho.ac.id
}

\begin{abstract}
Abstrak
Dismenorea merupakan nyeri perut yang berasal dari kram rahim yang terjadi selama haid. Dismenorea primer itu sendiri adalah perasaan sangat nyeri saat menstruasi yang terjadi tanpa kelainan ginekologi, sering dimulai pada 6-12 bulan setelah menarche, dan dapat berlanjut hingga menopause, serta terjadi bersamaan dengan menstruasi dan dapat berlanjut selama 8 jam sampai 3 hari. Penelitian ini bertujuan untuk mengetahui Hubungan Tingkat Stres, Kualitas Tidur, dan Aktifitas Fisik Dengan Kejadian Dismenorea Primer pada Mahasiswi Fakultas Kesehatan Masyarakat Universitas Halu Oleo Tahun 2020. Metode penelitian ini menggunakan penelitian kuantitatif dengan pendekatan cross sectional study. Penelitian ini menggunakan teknik penarikan sampel probability sampling dengan menggunakan Propotional Random Sampling. Populasi dalam penelitian ini berjumlah 789 orang dan sampel pada penelitian ini berjumlah 258 orang. Hasil penelitian ini menunjukkan korelasi yang signifikan antara tingkat stres dan Dismenore Primer ( $\varrho$ Value $=0,000,<0,05)$. Sementara itu, tidak ada korelasi yang signifikan antara kualitas tidur dan Dismenore Primer $(\varrho$ Value $=0,202,>0,05)$ dan antara aktifitas fisik dengan Dismenore Primer $(\varrho$ Value $=0,725,>$ 0 , 05). Kesimpulannya yaitu ada korelasi antara tingkat stres dengan kejadian dismenore primer pada mahasiswi Fakultas Kesehatan Masyarakat Universitas Halu Oleo.
\end{abstract}

Kata Kunci : $\quad$ Kualitas Tidur, Aktivitas Fisik, Tingkat Stres, Dismenorea Primer

\begin{abstract}
Dysmenorrhoea is abdominal pain that comes from uterine cramps that occur during menstruation. Primary dysmenorrhoea itself is a feeling of intense pain during menstruation that occurs without gynecological abnormalities, often starts 6-12 months after menarche, and can continue until menopause, coincides with menstruation and can continue for 8 hours to 3 days. This study aims to determine the relationship between stress levels, sleep quality, and physical activity with the incidence of primary dysmenorrhoea in students of the Faculty of Public Health, Halu Oleo University in 2020. This research method uses quantitative research with a cross-sectional study approach. This study uses a probability sampling technique using proportional random sampling. The population in this study amounted to 789 people and the sample in this study amounted to 258 people. The results of this study showed a significant correlation between stress levels and primary dysmenorrhea ( $\varrho$ value $=0.000$, $<0.05)$. Meanwhile, there was no significant correlation between sleep quality and primary dysmenorrhea $(\varrho$ value $=$ $0.202,>0.05)$ and between physical activity and primary dysmenorrhea ( $\varrho$ value $=0.725,>0,05)$. The conclusion is that there is a correlation between stress levels and the incidence of primary dysmenorrhea in students of the Faculty of Public Health, Halu Oleo University.
\end{abstract}

Keywords : Sleep Quality, Physical Activity, Stress Levels, Primary Dysmenorrhoea 


\section{PENDAHULUAN}

Dismenorea merupakan nyeri perut yang berasal dari kram rahim yang terjadi selama haid. Rasa nyeri timbul bersamaan dengan permulaan haid dan berlangsung beberapa jam hingga beberapa hari hingga mencapai puncak nyeri ${ }^{1}$. Dismenorea menyebabkan dampak fisik berupa gangguan aktivitas dan pekerjaan serta dampak psikologis berupa kecemasan dan depresi. Dampak dismenorea dikaitkan dengan sejumlah masalah seperti kelemahan, keringat berlebihan, dan hilangnya nafsu makan gangguan pola tidur, sehingga menggangu kegiatan seharihari ${ }^{1}$.

Terdapat dua kategori dismenorea yaitu primer dan sekunder. Dismenorea primer adalah perasaan sangat nyeri saat menstruasi yang terjadi tanpa kelainan ginekologi, sering dimulai pada 6-12 bulan setelah menarche, dan dapat berlanjut hingga menopause, serta terjadi bersamaan dengan menstruasi dan dapat berlanjut selama 8 jam sampai 3 hari ${ }^{2}$. Dismenorea sekunder dapat terjadi kapan saja pada kehidupan perempuan, antara menarche dan menopause, namun paling sering terjadi setelah usia 25 tahun, dengan adanya keadaan patologis yang mendasari, seperti endometriosis dan kista ovarium² ${ }^{2}$.

Menurut World Health Organization (WHO) tahun 2013 angka kejadian nyeri haid di dunia sangat tinggi. Angka kejadian dismenorea sebesar 1.769.425 jiwa $(90 \%)$ dengan 10-15\% mengalami dismenorea berat. Rata-rata lebih dari $50 \%$ perempuan di setiap negara mengalami nyeri haid. Insiden nyeri haid pada remaja dilaporkan sekitar 92\%, Prevalensi dismenorea di Indonesia sebesar $64,25 \%$ yang terdiri dari $54,89 \%$ dismenorea primer dan $9,36 \%$ dismenorea sekunder ${ }^{3}$. Dismenorea primer dialami oleh $60-75 \%$ remaja, dengan tiga perempat dari jumlah remaja tersebut mengalami nyeri ringan sampai berat dan seperempat lagi mengalami nyeri berat ${ }^{3}$. Penelitian di Amerika Serikat menyebutkan bahwa dismenorea dialami oleh 30\%-50\% wanita usia reproduksi dan 10\%-15\% diantaranya kehilangan kesempatan kerja, mengganggu kegiatan belajar di sekolah dan kehidupan keluarga. Begitu pula angka kejadian dismenorea di Indonesia cukup tinggi, namun yang berobat ke pelayanan kesehatan sangatlah sedikit, yaitu hanya $1 \%-2 \%{ }^{3}$.

Fenomena Angka kejadian dismenorea di dunia sangat besar, rata-rata lebih dari $50 \%$ perempuan di setiap Negara mengalami nyeri menstruasi ${ }^{4}$. Di Amerika angka presentasenya sekitar 60\%-91\% dan dari Swedia dilaporkan nyeri haid pada $90 \%$ wanita yang berusia kurang dari 19 tahun dan 67\% wanita yang berusia 24 tahun. Angka kejadian dismenorea yang terjadi di beberapa negara lain cukup tinggi seperti yang Studi prevalensi di Meksiko (2010) sebanyak 64\% diantaranya mengalami dismenore ${ }^{4}$. Pada tahun 2012 di Mesir dilakukan studi epidemiologi di dapatkan $76,1 \%$ mengalami dismenore ditingkatan yang berbeda ${ }^{4}$. Sebuah penelitian yang dilakukan di India (2008) ditemukan prevalensi dismenore sebesar $73,83 \%$ di mana dismenore berat sebesar $6,32 \%$, dismenore sedang sebesar 30,37\% dan dismenore ringan sebesar 63,29\%

Prevalensi dismenorea di Indonesia angka kejadian dismenorea tipe primer adalah sekitar 54,89\% sedangkan sisanya penderita dengan dismenorea sekunder ${ }^{5}$. Dismenorea terjadi pada remaja dengan prevalensi berkisar antara 43\% hingga 93\%, dimana sekitar $7480 \%$ remaja mengalami dismenorea ringan, sementara angka kejadian endometriosis pada remaja dengan nyeri panggul diperkirakan 25-38\%, sedangkan pada remaja yang tidak memberikan respon positif terhadap penanganan untuk nyeri haid, endometriosis ditemukan pada $67 \%$ kasus. Kelainan terjadi pada 60-70\% wanita di Indonesia dengan 15\% diantaranya mengeluh bahwa aktivitas mereka menjadi terbatas akibat dismenorea ${ }^{5}$.

Survei pendahuluan pada mahasiswi Fakultas Kesehatan Masyarakat UHO didapatkan bahwa terdapat 20 mahasiswi pernah mengalami nyeri haid (Dismenorea) pada saat menstruasi, merasakan sakit pada bagian perut dan menjalar ke bagian pan.ggul, merasa kurang nyaman saat beraktivitas dan tidak bersemangat. Nyeri haid yang di rasakan oleh mahasiswi berbeda-beda, ada yang terjadi di awal menstruasi dengan tingkat nyeri sangat sakit dan juga pada saat menstruasi dengan tingkat nyeri yang ringan.

Berdasarkan latar belakang tersebut maka peneliti tertarik melakukan penelitian Kuantitatif dengan mengangkat judul tentang "Hubungan Kualitas Tidur, Aktifitas Fisik dan Tingkat Stres Dengan Kejadian Dismenorea Primer Pada Mahasiswai Fakultas Kesehatan Masyarakat Universitas Halu Oleo Tahun 2020”..

\section{METODE}

Jenis penelitian ini adalah kuantitatif dengan pendekatan analitik cross sectional study yaitu jenis penelitian yang menekankan waktu pengukuran variabel dependen dan variabel independen dinilai pada suatu saat, menurut keadaan pada waktu observasi. penelitian ini dilaksanakan di Fakultas Kesehatan Masyarakat Universitas Halu Oleo pada bulan Juli sampai Agustus tahun 2020. Populasi dalam penelitian ini adalah mahasiswi FKM UHO dengan jumlah 789. Sampel dalam penelitian ini berjumlah 258 responden. Teknik pengambilan sampel dalam penelitian ini adalah probability sampling dengan menggunakan Propotional Random Sampling. Analisis data dalam penelitian ini menggunkakan analisis univariat dan analisis bivariat.

\section{HASIL}

a. Analisis Univariat

Tabel 1. Distribusi Responden Berdasarkan Dismenorea Primer Pada Mahasiswi FKM UHO

\begin{tabular}{ccc}
\hline $\begin{array}{c}\text { Dismenorea } \\
\text { Primer }\end{array}$ & $\begin{array}{c}\text { Jumlah } \\
\text { (n) }\end{array}$ & $\begin{array}{c}\text { Persentase } \\
\text { (\%) }\end{array}$ \\
\hline Tidak nyeri & 146 & 56.6 \\
\hline Nyeri & 112 & 43.4 \\
\hline Total & 258 & 100 \\
\hline
\end{tabular}

Sumber: Data Primer, September 2020

Tabel 1 menunjukkan bahwa dari 258 responden, jumlah responden yang tertinggi mengalami Dismenorea Primer dengan kategori Tidak nyeri yaitu sebanyak 146 responden (56,6\%). 
Tabel 2. Distribusi Responden Berdasarkan Kualitas Tidur Pada Mahasiswi FKM UHO

\begin{tabular}{ccc}
\hline Kualitas Tidur & $\begin{array}{c}\text { Jumlah } \\
(\mathbf{n})\end{array}$ & $\begin{array}{c}\text { Persentase } \\
(\mathbf{\%})\end{array}$ \\
\hline Buruk & 202 & 78,3 \\
\hline Baik & 56 & 21,7 \\
\hline Total & 258 & 100
\end{tabular}

Sumber: Data Primer, September 2020

Tabel 2 menunjukkan bahwa dari 258 responden, jumlah responden tertinggi memiliki kualitas tidur buruk yaitu sebanyak 202 responden $(78,3 \%)$.

Tabel 3. Distribusi Responden Berdasarkan Aktifitas Fisik Pada Mahasiswi FKM UHO

\begin{tabular}{ccc}
\hline Aktifitas Fisik & $\begin{array}{c}\text { Jumlah } \\
\text { (n) }\end{array}$ & $\begin{array}{c}\text { Persentase } \\
(\mathbf{\%})\end{array}$ \\
\hline Ringan & 85 & 32,9 \\
\hline Sedang & 106 & 41,1 \\
\hline Berat & 67 & 26,0 \\
\hline Total & 258 & 100 \\
\hline Sumber: Data Primer, September 2020 &
\end{tabular}

Tabel 3 menunjukkan bahwa dari 258 responden, jumlah responden terbanyak yaitu memiliki aktifitas fisik sedang yaitu 106 responden (41,1\%),

Tabel 4. Distribusi Responden Berdasarkan Tingkat Stres Pada Mahasiswi FKM UHO

\begin{tabular}{ccc}
\hline Tingkat Stres & $\begin{array}{c}\text { Jumlah } \\
(\mathbf{n})\end{array}$ & $\begin{array}{c}\text { Persentase } \\
(\mathbf{\%})\end{array}$ \\
\hline Tidak Stres & 158 & 61,2 \\
\hline Stres & 100 & 38,8 \\
\hline Total & 258 & 100
\end{tabular}

Sumber: Data Primer, September 2020

Tabel 4 menunjukkan bahwa dari 258 responden, jumlah responden yang tertinggi memiliki tingkat stress dengan kategori tidak stress yaitu sebanyak 158 responden $(61,2 \%)$.

\section{b. Analisis Bivariat}

Tabel 5. Hubungan Kualitas Tidur Dengan Dismenorea Primer Pada Mahasiswi Fakultas Kesehatan Masyarakat UHO

\begin{tabular}{|c|c|c|c|c|c|c|c|}
\hline \multirow{4}{*}{$\begin{array}{c}\text { Kualitas } \\
\text { Tidur }\end{array}$} & \multicolumn{4}{|c|}{ Dismenorea Primer } & \multicolumn{2}{|c|}{ Total } & \multirow{4}{*}{ p Value } \\
\hline & \multirow{2}{*}{\multicolumn{2}{|c|}{$\begin{array}{l}\text { Tidak } \\
\text { Nyeri }\end{array}$}} & \multirow{2}{*}{\multicolumn{2}{|c|}{ Nyeri }} & \multirow{3}{*}{$\mathrm{n}$} & \multirow{3}{*}{$\%$} & \\
\hline & & & & & & & \\
\hline & $\mathrm{n}$ & $\%$ & $\mathrm{n}$ & $\%$ & & & \\
\hline Buruk & 119 & 81,5 & 83 & 74,1 & 202 & 78,3 & \\
\hline Baik & 27 & 18,5 & 29 & 25,9 & 56 & 21,7 & 0,202 \\
\hline Total & 146 & 100 & 112 & 100 & 258 & 100 & \\
\hline
\end{tabular}

Hasil penelitian menunjukkan bahwa dari 146 responden yang mengalami dismenorea primer tidak nyeri, pada umumnya mempunyai kualitas tidur yang buruk yaitu sebanyak 119 (81,5\%) responden. Sebaliknya, dari 112 responden yang mengalami dismenorea primer nyeri pada umumnya juga mempunyai kualitas tidur yang buruk yaitu sebanyak $83(74,1 \%)$ responden.

Hasil uji statistic Chi-Square pada taraf kepercayaan 95\% $(0,05)$ menunjukkan bahwa $\mathrm{p}$ Value $=0,202, \mathrm{p}$ Value $>0,05$, sehingga $\mathrm{H}_{1}$ di tolak dan $\mathrm{H}_{0}$ di terima, menunjukkan bahwa tidak ada hubungan yang signifikan antara kualitas tidur dengan dismenorea primer pada mahasiswi angkatan 2017-2019 Fakultas Kesehatan Masyarakat tahun 2020.

Tabel 6. Hubungan Aktifitas Fisik Dengan Dismenorea Primer Pada Mahasiswi Fakultas Kesehatan Masyarakat UHO

\begin{tabular}{|c|c|c|c|c|c|c|c|}
\hline \multirow{4}{*}{$\begin{array}{l}\text { Aktifitas } \\
\text { Fisik }\end{array}$} & \multicolumn{4}{|c|}{ Dismenorea Primer } & \multicolumn{2}{|c|}{ Total } & \multirow{4}{*}{$\begin{array}{c}\mathrm{p} \\
\text { Value }\end{array}$} \\
\hline & \multirow{2}{*}{\multicolumn{2}{|c|}{$\begin{array}{l}\text { Tidak } \\
\text { Nyeri }\end{array}$}} & \multirow{2}{*}{\multicolumn{2}{|c|}{ Nyeri }} & & & \\
\hline & & & & & $\mathrm{n}$ & $\%$ & \\
\hline & $\mathrm{n}$ & $\%$ & $\mathrm{n}$ & $\%$ & & & \\
\hline Ringan & 51 & 34,9 & 34 & 30,4 & 85 & 32,9 & \\
\hline Sedang & 59 & 40,4 & 47 & 42,0 & 106 & 41,1 & \\
\hline Berat & 36 & 24,7 & 31 & 27,7 & 67 & 26,0 & $0,72 b$ \\
\hline Total & 146 & 100 & 112 & 100 & 285 & 100 & \\
\hline
\end{tabular}

Sumber: Data Primer, September 2020

Hasil penelitian menunjukkan bahwa dari 146 responden yang mengalami dismenorea primer tidak nyeri, pada umumnya mempunyai aktifitas fisik sedang yaitu sebanyak 59 (40,4\%) responden. Sebaliknya, dari 112 responden yang mengalami dismenorea primer nyeri pada umumnya juga mempunyai aktifitas fisik yang sedang yaitu sebanyak $47(42,0 \%)$ responden.

Hasil uji statistic Chis-Square pada taraf kepercayaan 95\% $(0,05)$ menunjukkan bahwa $\mathrm{p}$ Value $=0,725, \mathrm{p}$ Value $>0,05$, sehingga $\mathrm{H}_{1}$ ditolak dan $\mathrm{H}_{0}$ diterima, menunjukkan bahwa tidak ada hubungan yang signifikan antara aktifitas fisik dengan dismenorea primer pada mahasiswi angkatan 2017-2019 Fakultas Kesehatan Masyarakat tahun 2020.

Tabel 7. Hubungan Tingkat Stres Dengan Dismenorea Primer Pada Mahasiswi Fakultas Kesehatan Masyarakat UHO

\section{Dismenorea Primer Total}

\begin{tabular}{|c|c|c|c|c|c|c|c|}
\hline \multirow{4}{*}{$\begin{array}{c}\text { Tingkat } \\
\text { Stres }\end{array}$} & \multirow{3}{*}{\multicolumn{2}{|c|}{$\begin{array}{l}\text { Tidak } \\
\text { Nyeri }\end{array}$}} & \multirow{3}{*}{\multicolumn{2}{|c|}{ Nyeri }} & & & \multirow{4}{*}{$\mathrm{p}_{\text {Value }}^{\mathrm{p}}$} \\
\hline & & & & & \multirow{3}{*}{$\mathrm{n}$} & \multirow{3}{*}{$\%$} & \\
\hline & & & & & & & \\
\hline & $\mathrm{n}$ & $\%$ & $\mathrm{n}$ & $\%$ & & & \\
\hline Tidak Stres & 85 & 58,2 & 27 & 24,1 & 112 & 43,4 & \\
\hline Stres & 61 & 41,8 & 85 & 75,9 & 146 & 56,6 & 0,000 \\
\hline Total & 146 & 100 & 112 & 100 & 285 & 100 & \\
\hline
\end{tabular}

Sumber: Data Primer, September 2020

Hasil penelitian menunjukkan bahwa dari 112 responden yang mengalami dismenorea primer nyeri, 
pada umumnya mengalami stres yaitu sebanyak 85 $(75,9 \%)$ responden. Sebaliknya, dari 146 responden yang mengalami dismenorea primer tidak nyeri, pada umumnya juga mengalami stres yaitu sebanyak 61 $(41,8 \%)$ responden.

Hasil uji statistic Chis-Square pada taraf kepercayaan $95 \%(0,05)$ menunjukkan bahwa $\mathrm{p}$ Value $=0,000, \mathrm{p}$ Value $<0,05$, sehingga $\mathrm{H}_{1}$ diterima dan $\mathrm{H}_{0}$ ditolak, menunjukkan bahwa ada hubungan yang di berikan antara tingkat stres dengan dismenorea primer pada mahasiswi angkatan 2017-2019 Fakultas Kesehatan Masyarakat tahun 2020.

\section{PEMBAHASAN}

\section{Hubungan Kualitas Tidur dengan Kejadian Dismenorea Primer pada Mahasiswi Fakultas Kesehatan Masyarakat UHO}

Kualitas tidur adalah ukuran dimana seseorang itu dapat kemudahan dalam memulai tidur dan untuk mempertahankan tidur, kualitas tidur seseorang dapat digambarkan dengan lama waktu tidur, dan keluhan keluhan yang dirasakan saat tidur ataupun sehabis bangun tidur ${ }^{6}$.

Kualitas tidur yang buruk akan memicu terjadinya stres, Ketika stres tubuh akan menghasilkan hormon adrenalin, estrogen, progesteron, dan PG yang berlebihan ${ }^{7}$ Estrogen dapat menyebabkan peningkatan kontraksi uterus secara berlebihan sedangkan progesteron bersifat menghambat kontraksi. Peningkatan kontraksi yang berlebihan ini menyebabkan rasa nyeri ${ }^{7}$. Selain itu, hormon adrenalin yang juga meningkat, akan menyebabkan otot tubuh tegang termasuk otot rahim, sehingga menimbulkan nyeri ketika menstruasi ${ }^{7}$.

Orlandi et al (2018) memperoleh hasil penelitian bahwa, perempuan yang memaksimalkan kualitas tidur, mengurangi konsumsi kafein dan alkohol, akan mengalami penurunan sensitivitas nyeri pada 3 bulan kemudian ${ }^{8}$. Hasil penelitian ini juga sejalan dengan hasil penelitian Roehrs et al (2017) yang membuktikan, bahwa penambahan durasi tidur terbukti menurunkan sensitivitas seseorang terhadap nyeri ${ }^{9}$. Selain itu, Heneweer et al (2017) dalam penelitiannya juga menyatakan, bahwa nyeri adalah suatu kondisi kompleks yang dipengaruhi oleh aktivitas tubuh dan kualitas tidur. Hal ini didukung oleh teori, bahwa perempuan pada rentang usia 18-25 tahun, membutuhkan tidur selama 7-9 jam setiap harinya ${ }^{10}$.

Dari hasil penelitian pada kuisioner, kualitas tidur buruk paling banyak dialami oleh mahasiswi Fakultas Kesehatan Masyarakat UHO yang menjadi subjek penelitian, yaitu dari 258 mahasiswi, 202 mahasiswi memiliki kualitas tidur buruk. Hal yang menyebabkan kondisi tersebut yaitu pada hasil pengisian kuisoner rata-rata mahasiswi tidur di jam 10 malam dan baru bisa tertidur sekitar 30 menit sampai 1 jam setelah berbaring, terbangun ditenga malam untuk ke kamar mandi, terbangun karena kedinginan, karena batuk, dan kemudian mahasiswi bangun di jam 4 atau 5 subuh untuk melaksanakan sholat subuh. Jadi dapat disimpulkan kualitas tidur mahasiswi tidak maksimal, dimana durasi tidur yang baik di malam hari yaitu sekitar 8 jam. Sedangkan jumlah yang mengalami kualitas tidur baik jauh lebih rendah, yaitu 56 mahasiswi.

Berdasarkan hasil kuisioner penelitian didapatkan lebih banyak mahasiswi yang memiliki kualitas tidur buruk dibandingkan kualitas tidur yang baik, namun mahasiswi yang memiliki kualitas tidur buruk mengalami derajat dismenorea primer tidak nyeri sebanyak $41,1 \%$ saat menstruasi. Hal ini disebabkan karena mayoritas perempuan yang mengalami menstruasi sering mengalami keterlambatan menstruasi, faktor yang menyebabkan yaitu stres, aktifitas fisik yang berat, kenaikan dan penurunan berat badan yang drastis, Polycystic Ovari Symptom (PCOS), memiliki riwayat penyakit kronis dan bermasalah pada tiroid 9 . Namun, masih didapatkan sebanyak $27,2 \%$ dan $24,3 \%$ yang memiliki kualitas tidur buruk dengan derajat dismenorea primer sedang maupun ringan.

\section{Hubungan Aktifitas Fisik dengan Kejadian Dismenorea Primer pada Mahasiswi Fakultas Kesehatan Masyarakat UHO}

Seseorang yang melakukan aktivitas fisik akan merangsang sekresi substansi yang dapat meningkatkan perasaan senang dalam otak, yang disebut endorfin diproduksi oleh kelenjar hipofisis dan hipotalamus. Endorfin atau "morfin endogen" (morfin yang diproduksi dalam tubuh) dapat meningkatkan ambang nyeri ${ }^{12}$. Endorfin juga meningkatkan mood dan memberi rasa senang serta menghasilkan analgesik dan membantu untuk menurunkan efek prostaglandin sehingga dapat mencegah nyeri saat menstruasi ${ }^{15}$. Melakukan aktivitas fisik dapat merangsang pengeluaran endorfin sehingga dapat memberi rasa nyaman serta menghasilkan analgesik non spesifik jangka pendek untuk mengurangi rasa nyeri ${ }^{12}$.

Penelitian ini sejalan dengan penelitian Khairunnisa (2017), dari hasil uji statistik menunjukkan bahwa tidak terdapat hubungan aktivitas fisik dengan nyeri haid (dismenorea) pada santriwati MAS Ulumuddin Uteunkot-Cunda Kota Lhokseumawe tahun 2016 ${ }^{13}$. Sama halnya dengan penelitian yang dilakukan Annisa Tristiana (2017), dengan hasil penelitian didapatkan tidak ada hubungan yang bermakna antara aktifitas fisik dengan kejadian dismenorea primer (Fisher, $p=0,372^{12}$. Hal ini disebabkan juga karena faktor psikosomatik yang kerap dialami oleh para anak remaja, termaksud pada responden yang usianya 14-19 tahun. Faktor psikomatik ini menyebabkan seorang memiliki ambang nyeri yang rendah sehingga dengan sedikit rangsang nyeri saja seseorang dapat mempersepsikan nyeri tersebut sebagai sesuatu yang mengganggu. Sebuah penelitian menyatakan bahwa dengan metode psikoanalisis, seorang dapat membuat sugesti pada dirinya jika nyeri tersebut dapat dihilangkan, sehingga rasa nyeri berkurang dan gejalanya hilang ${ }^{14}$.

Berdasarkan hasil penelitian pada kuisoner didapatkan jumlah responden pada kejadian dismenorea primer yang mengalami tidak nyeri pada 
kelompok aktifitas fisik sedang sebanyak 59 (40,4\%) responden. Sama halnya pada kejadian dismenore primer yang mengalami nyeri haid pada kelompok aktifitas fisik sedang sebanyak $47(42,0 \%)$ responden, jadi total responden yang memiliki aktifitas fisik sedang yaitu sebanyak $106(41,1 \%)$ responden. Hal yang menyebabkan yaitu pada pengisian kuisioner, mahasiswi memiliki aktifitas sedang selama seminggu (7 hari), dan dalam 1 hari itu mereka melakukan aktifitas sedang selama 1 jam bahkan sampai 7 jam. Aktifitas sedang sendiri itu yaitu aktifitas yang dapat menyebabkan nafas atau nadi sedikit lebih keras dari biasanya, dimana $40 \%$ dari waktu yang digunakan adalah untuk duduk dan berdiri dan $60 \%$ adalah untuk kegiatan kerja dalam bidang perkerjaan. Contoh nya seperti menyapu, mengepel, mencuci piring dan pakaian, membereskan tempat tidur serta memasak. Kemudian pada pertanyaan "apakah anda melakukan olahraga dengan intensitas yang sedang minimal 10 menit dalam seminggu terakhir"?. Jawaban mehasiswi "ya" dengan jumlah hari hanya sekitar 3 kali dalam seminggu, dengan durasi waktu 5-45 menit dalam sehari, seperti bersepeda ataupun berlari-lari kecil.

\section{Hubungan Tingkat Stres dengan Kejadian Dismenorea Primer pada Mahasiswi Fakultas Kesehatan Masyarakat UHO}

Stress terhadap nyeri saat menstruasi dapat terjadi karena stress melibatkan sistem neuroendokrin sebagai sistem yang besar perannya dalam reproduksi wanita ${ }^{14}$. Nyeri saat menstruasi akan memengaruhi proses biokimia dan seluler seluruh tubuh termasuk otak dan psikologis ${ }^{15}$. Saat stress, tubuh akan memproduksi hormon adrenal, estrogen, progesteron serta prostaglandin yang berlebihan. Meningkatnya hormone estrogen, dapat menyebabkan terjadinya peningkatan kontraksi uterus yang berlebihan ${ }^{15}$. Selain itu, peningkatan hormone adrenalin dapat menyebabkan terjadinya ketegangan otot rahim, kondisi ini membuat kontraksi berlebihan sehingga akan menimbulkan rasa nyeri ${ }^{15}$.

Penelitian ini bukan penelitian yang pertama yang menunjukkan adanya hubungan antara tingkat stres dengan siklus menstruasi. Hasil yang sama didapatkan oleh Naumi Wahyu Fitria (2017) ${ }^{15}$. Terdapat hubungan tingkat stres dengan kejadian dismenore pada mahasiswi DIV Kebdianan Universitas 'Aisyiyah Yogyakarta Tahun 2017 dengan nilai signifikan $0,046(<0,05)$ dan koefisien korelasi 0,269 yaitu dengan keeratan hubungan yang rendah ${ }^{15}$. Penelitian yang sama di lakukan oleh Fidora dan Okrira (2019) penelitian ini dilaksanakan untuk mengetahui hubungan antara tingkat stres dengan gangguan siklus menstruasi pada remaja putri di SMK Pembina Bangsa Bukittinggi. Yang menunjukkan adanya hubungan antara tingkat stres dengan gangguan siklus menstruasi pada remaja ${ }^{16}$.

Pada saat stres, melalui saraf indra stresor akan diteruskan ke bagian saraf otak yang disebut lymbic system (neurotransmitter), selanjutnya stimulus akan diteruskan ke kelenjar-kelenjar hormonal (endokrin) yang merupakan sistem imunitas tubuh dan organ- organ tubuh yang dipersyarafinya ${ }^{17}$. Stimulus tadi akan mengakibatkan produksi hormon adrenalin meningkat kemudian masuk ke peredaran darah dan mempengaruhi jantung (berdebar-debar), tekanan darah meninggi, asam lambung meningkat, emosi tidak terkendali, dan lain sebagainya ${ }^{17}$. Gangguan pada sistem endokrin yang mngalami stres berupa gangguan menstruasi yang tidak teratur dan dismenorea ${ }^{17}$. pada saat stres, tubuh akan memproduksi hormon adrenalin, estrogen, progesteron serta prostaglandin yang berlebihan, Estrogen dapat meningkatkan kontraksi uterus, Meningkatnya hormon adrenalin juga menimbulkan otot tubuh tegang termasuk otot rahim yang berakibat pada penurunan perfusi ke jaringan endometrium, sehingga pembuluh darah terjepit oleh otot uterus yang menyebabkan suplai oksigen berkurang dan menjadi iskemik ${ }^{17}$.

Pada hasil penelitian pada mahasiswi Fakultas Kesehatan Masyarakat UHO dengan derajat dismenorea primer Tidak nyeri didapatkan 85 (58,2\%) mahasiswi yang tidak mengalami stres. Hal ini disebabkan sebagian besar mahasiswi memiliki banyak waktu luang untuk beristrahat saat pandemi covid-19. Namun, didapatkan pada derajat dismenorea primer Nyeri sebanyak $85(75,9 \%)$ mahasiswi dan yang tidak nyeri sebanyak $61(41,8 \%)$ responden. Hal ini disebabkan sebagian mahasiswi sedang melakukan praktek lapangan akhirnya sulit untuk beristrahat, serta karena adanya pandemi mahasiswi semakin takut untuk melakukan kegiatan diluar rumah membuat mahasiswi mudah merasa gelisah, kesal dan marah, banyak tugas kuliah menumpuk yang harus diselesaikan, dan pola makan mereka yang buruk akhirnya membuat mahasiswi tersebut mudah stres.

\section{SIMPULAN}

1. Ada hubungan antara Tingkat stres dengan Dismenorea Primer pada Mahasiswi Fakultas Kesehatan Masyarakat Tahun 2020.

2. Tidak ada hubungan yang signifikan antara kualitas tidur dengan Dismenorea Primer pada Mahasiswi Fakultas Kesehatan Masyarakat Tahun 2020.

3. Tidak ada hubungan yang signifikan antara aktifitas fisik dengan Dismenorea Primer pada Mahasiswi Fakultas Kesehatan Masyarakat Tahun 2020.

\section{SARAN}

1. Diharapkan kepada mahasiswi Fakultas Kesehatan Masyarakat, agar menghindari stres, memperhatikan kualitas tidur, dan selalu melakukan aktifitas fisik yang baik agar mengurangi rasa nyeri pada saat menstruasi.

2. Diharapkan kepada peneliti selanjutnya untuk dapat melakukan penelitian secara mendalam mengenai faktor-faktor lain yang dapat menyebabkan terjadinya rasa nyeri saat menstruasi.

3. Di harapkan kepada peneliti selanjutnya, agar menggunakan waktu yang tepat saat memberikan kuesioner kepada responden. 
4. Di harapkan kepada peneliti selanjutnya, dapat melakukan tatap muka langsung saat membagikan kuisioner agar responden lebih memahami apa maksud dari isi kuisioner tersebut.

\section{DAFTAR PUSTAKA}

1. Sholihah, J. 2016. Hubungan tipe kepribadian ekstrovert dan introvert dengan tingkat kecemasan remaja yang mengalami dismenorea di smpn 11 jember. Skripsi program studi ilmu keperawatan universitas jember (hal. 17-26).

2. Proctor ML, Farquhar CM. (2017). Dysmenorrhea. British Medical Journal; 2007 [Disitasi pada 2017 Aug 2]: 3: 813-838.

3. Fitri Apriyanti, Elvira Harmia, Rika Andriani. (2018). Hubungan Status Gizi Dan Usia Menarche Dengan Kejadian Dismenore Pada Remaja Putri di SMAN 1 Bangkinang Kota Tahun 2018. Jurnal Maternitas Kebidanan, Vol 3, No. 2, Oktober 2018. ISSN 2599-1841.

4. Rifqah Utami, Andi Nurul. Jamriani Ansar. Dian Sidik. (2013). Faktor yang Berbubungan dengan Kejadian Dismenore pada Remaja Putri di SMAN 1 Kabu Kabupaten Bone. Jurnal Fakultas Kesehatan Masyarakat, UNHAS, Makassar.

5. Riskesdas. (2010). Kesehatan Reproduksi. Badan Penelitian Pengembangan Kesehatan Kementrian Kesehatan.

6. Deaneva AM, Fraser K, Rumana N, Abdullah AF, Shaha N, Hanly PJ, et al. (2015). Siklus Menstruasi Pada Dokter. Nexus Kedokt Komunitas. 2015;4(2):59-69. Diakses Pada November 2018.

7. Dwi Rafita Lestari, Mila Citrawati, Niniek Hardini. (2018). Hubungan aktivitas fisik dan kualitas tidur dengan dismenorea pada mahasiswi FK UPN "Veteran" Jakarta. Fakultas Kedokteran UPN "Veteran", Jakarta. Vol. 41, No. 2, Mei 2018, Hal. 48-58.

8. Orlandi AC, Ventura C, Gallinaro AL, Costa RA, Lage LV. Improvement in pain, fatigue, and subjective sleep quality through sleep hygiene tips in patients with fibromyalgia. Rev Bras Reumatol. 2012 [Disitasi pada 2018 Jan 1]; 52: 666-678. Tersedia di https://www.ncbi.nlm.nih.gov/pmc/articles/PMC 3490359/pdf/aasm.35.12.1667.pdf

9. Roehrs TA, Harris E, Randall S, Roth T. Pain sensitivity and recovery from mild chronic sleep loss. Sleep. 2012 [Disitasi pada 2017 July 20]; 35: 1667-1672. Tersedia

https://www.ncbi.nlm.nih.gov/pmc/articles/PMC 3490359/pdf/aasm.35.12.1667.pdf

10. Heneweer H, Vanhees L, Picavet HSJ. Physical activity and low back pain: A U-shaped relation? Pain. 2009 [Disitasi pada 2017 July 28]; 143: 21-25. Tersedia di:https://www.ncbi.nlm.nih.gov/pubmed/192172 08

11. Risky Candra Swari, 2020. Penyebab Telat Haid. $\begin{array}{lll}\text { Artikel } & 20 & \text { nobember }\end{array}$ https://hellosehat.com/kesehatan/penyakit/telathaid/\#gref

12. Annisa, Tristiana. (2017). Hubungan Aktifitas Fisik Dengan Kejadian Dismenorea Primer Pada Santri Di Pondok Pesantren X Di Kabupaten Bogor. Fakultas Kedokteran dan Ilmu Kesehatan, Universitas Islam Negeri Syarif Hidayaullah, jakarta.

13. Khairunnisa Khairunnisa, Nora Maulina, 2017. HUBUNGAN AKTIVITAS FISIK DENGAN NYERI HAID (DISMENOREA) PADA SANTRIWATI MADRASAH ALIYAH SWASTA ULUMUDDIN UTEUNKOT CUNDA KOTA LHOKSEUMAWE. Averrous, Vol. 3: No. 1 (Mei, 2017)

14. Faramarzi M, Salmalian H. (2017). Association of Psychologic and Nonpsychologic Factor With Primary Dysmenorrbea. Iran Red Crescent Med J,2017;(8);e16307

15. Naumi Wahyu Fitriana. (2017). Hubungan Tingkat Stres Dengan Kejadian Dismenore Pada Mahasiswa d IV Kebidanan Semester VIII Universitas 'Aisyiyah Yogyakarta. Skripsi Program Studi Kebidanan Jenjang Diploma IV Fakultas Ilmu Kesehatan Universitas 'Aisyiyah Yogyakarta.

16. Irma Fidora , Yosi Okrira. (2019). TINGKAT STRES DENGAN GANGGUAN SIKLUS MENSTRUASI REMAJA. JKSP Volume 2 Nomor 1, 28 Februari 2019. Jurnal Kesehatan Saelmakers Perdana ISSN 2615-6571 (Print), ISSN 2615-6563 (Online) Tersedia online di http://ojs.ukmc.ac.id/index.php/JOH.

17. Sri Rejeki, Nikmatul Hayati, Riski Yunita S. (2019). Hubungan Tingkat Stres dan Karakteristik Remaja Putri Dengan Kejadian Dismenore Primer. Praktisi dan Dosen Keperawatan Maternitis FIKKES UNIMUS. Jurnal Kebidanan, 8 (1), 2019,50-55 